\title{
La estructura municipal de Castilla y León: incidencia de la legislación sobre Régimen Local, Urbanismo y Ordenación del Territorio
}

\author{
Dionisio Fernández de Gatta Sánchez \\ Profesor Titular de Derecho Administrativo \\ Facultad de Derecho. Universidad de Salamanca \\ Diplomado en Planeamiento Urbanístico \\ Vocal de la Comisión Territorial de Urbanismo de Salamanca
}

SUMARIO: I. LA ESTRUCTURA MUNICIPAL Y LA SITUACIÓN TERRITORIAL DE CASTILLA Y LEÓN ANTE LAS NUEVAS LEYES. II. LAS COMPETENCIAS DE LA COMUNIDAD AUTÓNOMA DE CASTILLA Y LEÓN SOBRE RÉGIMEN LOCAL, URBANISMO Y ORDENACIÓN DEL TERRITORIO. III. INSTRUMENTOS PREVISTOS EN LA LEY DE RÉGIMEN LOCAL DE CASTILLA Y LEÓN CON RELACIÓN A LOS PROBLEMAS DE LA ESTRUCTURA MUNICIPAL. IV. LAS ADMINISTRACIONES LOCALES EN LAS LEYES DE URBANISMO Y ORDENACIÓN DEL TERRITORIO DE CASTILLA Y LEÓN. BIBLIOGRAFÍA CITADA.

\section{LA ESTRUCTURA MUNICIPAL Y LA SITUACIÓN TERRITORIAL DE CASTILLA Y LEÓN ANTE LAS NUEVAS LEYES}

Sobre los 8.101 municipios con que cuenta España, la Comunidad de Castilla y León se integra por 2.248 municipios, ocupando el primer puesto de todas la Comunidades Autónomas (seguida, a bastante distancia, por Cataluña, con 945, y Castilla-La Mancha, con 916 municipios); para una extensión de $94.224 \mathrm{Km}^{2}$.

Pero, además de tener un elevado número de municipios, Castilla y León tiene el mayor número de los municipios más pequeños de España:

- 1.957 municipios tienen menos de 1.000 habitantes, de los que 1.657 tienen menos de 500 habitantes y 1.138 menos de 250 habitantes.

- 2.200 municipios tienen menos de 5.000 habitantes.

- Únicamente 48 municipios tienen más de 5.000 habitantes, de los que 14 superan los 20.000 habitantes y 22 municipios los 10.000 habitantes. 
- Exclusivamente 4 municipios superan los 100.000 habitantes (Valladolid, Salamanca, Burgos y León).

Por provincias, Burgos, con 371 municipios, y Salamanca, con 362 municipios ocupan los primeros lugares en Castilla y León, seguidas, por Ávila y Zamora, con 248 municipios, respectivamente, teniendo la mayoría de esos municipios menos de 1.000 habitantes.

Además, debe tenerse en cuenta que existen 2.230 Entidades Locales Menores.

Esta preocupante situación está claramente consolidada ya que, prácticamente, no ha variado desde 1981, aunque haya oscilado el número total de municipios algún año.

Castilla y León, además, tiene una población dispersa, en general; si bien su mayoría se concentra en los 48 municipios con más de 5.000 habitantes: sobre los 2.480 .369 habitantes totales, a 1 de enero de 2002 (R.D. $1431 / 2002$, de 27 de diciembre, $B O E$ del 28), en estos municipios residen 1.513.239 personas, de ellos 787.428 habitantes en los 4 municipios con más de 100.000 habitantes censados. Por el contrario, en los 1.957 municipios menores de 1.000 habitantes, únicamente residen 541.495 personas, y en los 2.200 menores de 5.000 censados residen 993.267 habitantes.

Además, hay que tener en cuenta que, según datos del Instituto Nacional de Estadística, la población castellano-leonesa cayó entre 1986 y 1996 en 73.831 habitantes, pasando de 2.582 .327 en 1986 a 2.508 .496 en 1996, perdiendo un 2'86\% de población, cuando el número de habitantes del país creció un 3'11\%. que entre 1996 y 1998 ha perdido otros 23.893 habitantes, hasta llegar a 2.484.603 habitantes y que en 2002 ha pasado a tener 2.480.369 habitantes. Por provincias, la mayor pérdida poblacional, en este mismo período, le corresponde a Ávila, Zamora, Palencia y Soria, en función de su propio censo, aunque la pérdida de población es general. Es más, la proyección de población para el año 2005, realizada por el propio INE, en agosto de 1999, prevé un descenso de la población de Castilla y León de un $2 \%$ respecto a 1998, en que llega a 2.484.603 habitantes (sobre 50.000 habitantes), corroborándose esta situación con los datos señalados de 2002.

Esta pérdida generalizada de población se debe a causas económicas (emigración de jóvenes por motivos laborales) y al crecimiento vegetativo negativo de la población regional, teniendo en cuenta el preocupante envejecimiento de los castellano-leoneses (y que tales jubilados viven en más del $50 \%$ en municipios rurales menores de 2.000 habitantes). 
Por tanto, a pesar de haber disminuido drásticamente la población rural de Castilla y León (del 60\% en 1960 se ha pasado al 30\% en 1996), ésta sigue repartida en un número de municipios similar, con lo que es claro el progresivo deterioro poblacional de éstos. Es decir, los desequilibrios proceden del excesivo número de municipios pequeños.

En conclusión, Castilla y León se encuentra en la actualidad con dos tendencias: la existencia de muchos municipios con escasa población, por un lado, y una fuerte concentración de la población en municipios mayores de 10.000 habitantes, por otro lado; siendo esta última muy acusada en los últimos años y con perspectivas de consolidarse. Además, la pérdida general de población debe ser resaltada por sus consecuencias en relación con ayudas financieras estatales y en relación con la prestación de servicios públicos.

A los problemas anteriores hay que añadir (aunque con carácter general, y no sólo referido a Castilla y León) el aumento progresivo de las funciones y obligaciones de los municipios, previstas en el ordenamiento jurídico, aplicable a todos ellos, sin distinción de su situación real.

En la actualidad, el artículo 26 de la Ley de Bases de Régimen Local, de 1985, modificada en 1999, define los servicios mínimos que han de prestarse por los municipios, según su población; servicios que constituyen verdaderas competencias municipales. Además, tales servicios pueden ser exigidos por los vecinos, basándose en el artículo 18-LBRL, como esgrime la STS de 25-abril-1989, AR.3233, si bien los Tribunales no siempre lo hayan aceptado.

El gran número de municipios existente, su dispersión geográfica, su escasa población y su clara regresión económica, junto a la disminución y envejecimiento de la población traen consigo que tales Municipios (pues, esos núcleos de población conservan la condición de Municipios) no puedan, en la práctica, prestar y cumplir sus obligaciones legales y servicios mínimos, es decir, no puedan autogobernar sus propios intereses (tal como expresa con claridad la Exposición de Motivos de la Ley de Régimen Local de Castilla y León).

Durante la vigencia de la LS de 1956 se elaboraron pocos Planes Urbanísticos en España y en Castilla y León. En 1972, sólo el 16,1\% de los municipios españoles tenían planeamiento general.

En 1977, ya con la LS de 1976, el porcentaje, incluyendo los PDSU, alcanza ya al $25 \%$ del total de los municipios (si bien existen diferencias 
muy notables en función de las Comunidades Autónomas: Extremadura, con el 8\%; Aragón, con el 12\%; Castilla y León, con el 14\%, o La Rioja con el 15\%; frente al 92\% de Madrid o el 70\% del País Vasco), incluyendo 2.160 Municipios (991-PGM, 346-NSM y 823-PDSU), y el 76\% de la población total (27 millones de habitantes), con 8.702 municipios.

La gran mayoría de los Municipios con Planeamiento General tenían entre 1.000 y 25.000 habitantes, en concreto 1.228 Municipios. Por el contrario, de los 5.387 Municipios de menos de 1.000 habitantes, únicamente 735 contaban con Planeamiento. Es más, de los 7.669 Municipios con menos de 5.000 habitantes, sólo 1.446 tenían Planeamiento General.

En 1992, el porcentaje alcanza ya al $65 \%$ del total de los municipios (8.077), es decir, a 5.216 municipios [si bien aún con diferencias importantes entre las diferentes Comunidades Autónomas: desde el $100 \%$ en Madrid o Murcia, el 99\% en Baleares, el 98\% en Canarias o Extremadura o el $97 \%$ en la Comunidad Valenciana, al $42 \%$ en Castilla y León, el 50\% en Aragón o el 54\% en Castilla-La Mancha], mediante 795 PGM, 2.350 NSN y 2.071 PDSU, incluyendo el 95\% de la población total (37 millones habitantes).

Sobre los 4.964 municipios con más de 1.000 habitantes, 2.506 tenían planeamiento general (88 PGM, 868 NSM y 1.550 PDSU), y entre $1.000 \mathrm{y}$ 5.000 habitantes, que suponen 2.039 municipios, contaban con 1.667 instrumentos de planeamiento general (187-PGM; 1.027-NSM y 453-PDSU).

Con fecha de 3 de octubre de 1996, únicamente 38 municipios tenían adaptado su planeamiento al TRLS de 1992.

Posteriormente, en septiembre de 1998, el porcentaje de municipios con planeamiento general (PGM, NSM y PDSU) alcanza al 70,4\% (5.699 municipios), mediante 728-PGM, 3.059-NSM y 1.937-PDSU, incluyendo el 97,1\% de la población total; quedando, no obstante, aún, 2.373 municipios sin planeamiento. Respecto a Castilla y León, en esta época, cuenta con 1.079 municipios con planeamiento general (48\%), frente a los 1.168 municipios sin planeamiento (52\%); de los que 45 son PGM, 367 son NSM y 667 son PDSU. Sin embargo, el 86,1\% de la población de Castilla y León cuenta con planeamiento general. Desde 1992, en Castilla y León se aprobaron 15 PGM, 220 NSM y 172 PDSU.

Respecto a Castilla y León, con datos de 2000, los municipios con planeamiento general (PGM, NSM y PDSU) aumentan a 1.147 (51\%), superando ya a los municipios sin planeamiento (1.101 municipios, que repre- 
sentan el $49 \%$ del total). Los municipios con planeamiento se resumen en 467-PGM y NSM y 688-PDSU; llegando al 87\% de la población, y de los 548 con PDSU en 1991 se ha pasado a 688 municipios. Es decir, de los 771 municipios con planeamiento (incluyendo los PDSU), se ha pasado a 1.147 municipios, reduciéndose, por tanto, los municipios sin planeamiento de 1.479 en 1991 a 1.101 en 1999. Tendencia que ha continuado hasta la actualidad.

\section{LAS COMPETENCIAS DE LA COMUNIDAD AUTÓNOMA DE CASTILLA Y LEÓN SOBRE RÉGIMEN LOCAL, URBANISMO Y ORDENACIÓN DEL TERRITORIO}

De acuerdo con lo previsto en la Constitución, el artículo 27 del Estatuto de Autonomía de Castilla y León (Ley Orgánica 4/1983, de 25 de Febrero, $B O E$ del 2 de marzo) señala que, en el marco de la legislación básica del Estado y en los términos que ella misma establezca, le corresponde a la Comunidad «el desarrollo y la ejecución» de la legislación estatal sobre «alteraciones de términos municipales y las que correspondan a la Administración del Estado sobre corporaciones locales cuya transferencia autorice la legislación sobre régimen local»; correspondiéndole, además, a Castilla y León la potestad reglamentaria, la gestión y la función ejecutiva, incluida la inspección.

Teniendo en cuenta la Disposición Adicional 1. ${ }^{\mathrm{a}}$-LBRL, en una interpretación algo forzada, podemos señalar que Castilla y León podría intervenir legislativamente en materia de régimen local, en el marco de la legislación básica del Estado.

La Ley Orgánica 9/1992, de 23 de diciembre (BOE del 24), de Transferencias de Competencias a las Comunidades Autónomas de segundo grado, no se refiere a las Administraciones Locales, pues se había aceptado que estas Comunidades pudiesen intervenir legislativamente tanto en materia de alteración de términos municipales como en relación a las entidades inframunicipales y supramunicipales.

La reforma del Estatuto de Castilla y León, prevista en los Pactos Autonómicos de 1992, y llevada a cabo por Ley Orgánica 11/1994, de 24 de marzo (BOE del 25), continúa con la misma redacción del artículo $27-6 .^{\circ}$ del EACYL, sin solucionar los problemas interpretativos señalados (cuestión que, p. ej., sí despejó la Ley Orgánica 1/1994, de 25 de marzo, BOE del 25, modificando el Estatuto de Autonomía de Asturias, al incluir el «régimen local» entre las materias de su competencia de desarrollo legislativo). 
La última reforma del Estatuto de Castilla y León, llevada a cabo mediante Ley Orgánica 4/1999 de 8 de enero (BOE del 9), ha solucionado esta cuestión al incluir el «régimen local» entre las materias objeto de competencias de desarrollo legislativo y ejecución de la normativa estatal,

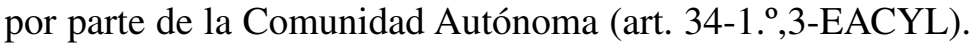

Además, hay que señalar que esta reforma permite la regulación general de las comarcas y se reserva a una ley autonómica la regulación de las entidades locales menores, las mancomunidades y otras formas de agrupación de municipios (art. 25-EACYL).

Respecto a las otras materias la Constitución establece, como es sabido, un aparente sencillo esquema de distribución de competencias entre el Estado y las Comunidades Autónomas. Así, el artículo 148-13, Const., señala que las Comunidades Autónomas podrán asumir competencias en materia de «ordenación del territorio, urbanismo y vivienda».

Basándose en ello, todos los Estatutos de Autonomía han asumido las competencias sobre ordenación del territorio y urbanismo, con el carácter de exclusivas; si bien con redacciones distintas. En estas materias, por tanto, las Comunidades Autónomas ostentan las potestades legislativa, reglamentaria y la ejecutiva o de gestión, incluyendo la inspección.

La Comunidad de Castilla y León se enmarca en la línea señalada, y prevé las materias de «ordenación del territorio y urbanismo» como de competencia exclusiva, tanto en la redacción original del Estatuto de Autonomía, de 1983 (art. 26-1. ${ }^{\circ}$,2), como en la reforma de 1994 (manteniéndose el mismo precepto), y, actualmente, en la redacción dada al Estatuto de Autonomía por Ley Orgánica 4/1999, de 8-enero (BOE del 9), en el nuevo artículo 32-1. ‥2, manteniendo la misma extensión de la competencia (art. 32-2. ${ }^{\circ}$ ).

No obstante la amplitud del reconocimiento de la competencia a favor de las Comunidades Autónomas, es evidente que no se pueden obviar una serie de competencias del Estado que inciden sobre el territorio.

En este sentido, la STC 61/1997, de 20-marzo (F.J. n. ${ }^{\circ} 16$ ) señala que:

«Es claro que delimitar los diversos usos a que puede destinarse el suelo o espacio físico constituye uno de los aspectos básicos del urbanismo y, en términos más generales, de la ordenación del territorio, pero ello no puede significar, en el plano competencial, que cualquier norma que incida sobre el territorio, siquiera sea de forma mediata o negativa, tenga que quedar subsumida en la competencia autonómica sobre ordenación del territorio, puesto que ello supondría atribuirse un alcance tan amplio que desconocería el contenido específico de otros muchos títulos competenciales, no sólo del Estado...» 
En parecidos términos, y con un excelente resumen de su doctrina anterior, se expresa la STC 149/1998, de 2 de julio (relativa a la Ley de Ordenación del Territorio del País Vasco, de 1990), al señalar que (F.J. n.3):

\begin{abstract}
«... la exclusividad con que las Comunidades Autónomas,..., han asumido la competencia en materia de ordenación territorial no autoriza a desconocer las que, con el mismo carácter, vienen reservadas al Estado en virtud del artículo 149.1 CE [SsTC $56 / 1986$, fundamento jurídico $3 .^{\circ}, 149 / 1991$, fundamento jurídico $1 .{ }^{\circ} \mathrm{B}$ ], cuyo ejercicio puede condicionar ciertamente la competencia autonómica [STC 61/1997, fundamento jurídico $\left.5 .^{\circ}\right] \ldots »$.
\end{abstract}

En el mismo sentido incide la STC 306/2000, de 12 de diciembre (FJ n. ${ }^{\circ}$ 5), relativa al Parque Nacional de los Picos de Europa.

Las competencias del Estado que inciden sobre las autonómicas en materia de urbanismo y ordenación del territorio son, entre las más destacables, las siguientes:

- puertos y aeropuertos, obras públicas de interés general; ferrocarriles y transportes terrestres que afectan a varias Comunidades Autónomas; aprovechamientos hidráulicos y forestales, vías pecuarias (Apdos. 20 a 24, art. 149-Const.);

- planificación de la actividad económica y régimen minero y energético (Apdos. 13 y 25, art. 149-Const.);

- defensa y seguridad pública; patrimonio artístico y cultural; sanidad (Apdos. 4, 16, 28 y 29, art. 149-Const.);

- medio ambiente (art. 149-1. ${ }^{\circ}, 23$, Const.);

- condiciones básicas que garanticen la igualdad de todos los españoles en el ejercicio de los derechos y en el cumplimiento de los deberes constitucionales (art. 149-1. ${ }^{\circ}, 1$, Const).

Por otra parte, se han de tener en cuenta las Administraciones Locales. Como es sabido, la Constitución reconoce (arts. 2, 137 y 140), y el Estatuto de Autonomía de Castilla y León (art. 25) reitera, la autonomía de las Entidades Locales; que, entre otras cuestiones, supone el reconocimiento de un ámbito competencial propio, el cual se determina concretamente en las Leyes estatales y autonómicas sectoriales o generales. No obstante, la Ley 7/1985, de 2 de abril, de Bases del Régimen Local (BOE del 3), modificada por Ley 11/1999, de 21 de abril (BOE del 22), precisa el contenido mínimo y homogéneo de tal ámbito competencial, para todo el territorio nacional. 
Así, el artículo 25-LBRL prevé que los Municipios ejercerán competencias en los términos previstos en la legislación del Estado y de las Comunidades Autónomas en la materia, entre otras, de ordenación, gestión, ejecución y disciplina urbanística; promoción y gestión de viviendas; parques y jardines, pavimentación de vías públicas urbanas y conservación de caminos y vías rurales (letra d); que constituyen, sin duda, las competencias más importantes en la materia. Además, hay que tener en cuenta otras materias previstas en el mismo precepto, estrechamente relacionados con el urbanismo y la ordenación del territorio. De acuerdo con el concepto de autonomía local, garantizada por la Constitución, sobre las materias previstas en el artículo 25-2. ${ }^{\circ}$. LBRL, los Municipios deben disponer de competencias, tienen el derecho a intervenir en las mismas, si bien en los términos previstos en la legislación estatal y autonómica. Respecto a la materia de ordenación del territorio, es claro que no se menciona en la LBRL, ya que se debe considerar una materia de interés supralocal, respecto a la cual las Corporaciones Locales poco pueden hacer.

En parecidos términos, como no podía ser de otra forma, el artículo 20 de la Ley 1/1998, de 4 de julio, de Régimen Local de Castilla y León (BOCL del 11), reconoce las competencias urbanísticas municipales, en los términos previstos en la legislación estatal y de la Comunidad Autónoma.

Respecto a las Provincias, el artículo 36-LBRL también se remite a la legislación estatal y autonómica de los diferentes sectores de la acción pública para la concreción de sus competencias; y, en todo caso, la coordinación de servicios municipales para asegurar la prestación de los servicios mínimos, la asistencia y cooperación con los Municipios, la prestación de servicios supralocales y supracomarcales, y el fomento y administración de los intereses peculiares de la provincia. En parecido sentido se expresa el artículo 5-3. ${ }^{\circ}$ de la Ley de Régimen Local de Castilla y León.

Finalmente, en el ámbito local, deben tenerse en cuenta las posibilidades previstas tanto en la LBRL como en la Ley de Régimen Local de Castilla y León de crear diversos entes y órganos, que podrán intervenir en materia urbanística.

\section{INSTRUMENTOS PREVISTOS EN LA LEY DE RÉGIMEN LOCAL DE CASTILLA Y LEÓN CON RELACIÓN A LOS PROBLEMAS DE LA ESTRUCTURA MUNICIPAL}

El problema de la estructura municipal, en particular en lo relativo al número de municipios y a su población, y su relación con las funciones 
que han de prestar a los ciudadanos, está presente en España desde la etapa de las Cortes de Cádiz en que, mediante Decreto de 23 de mayo de 1812, se hace equivalente núcleo de población y Municipio-Ayuntamiento. El debate ha girado históricamente sobre la entidad de los pequeños núcleos para prestar sus funciones y servicios, y, según épocas, sobre la necesidad de reducir el número de municipios.

La Constitución de 1978 ha introducido el reconocimiento de la autonomía local, entendida como el derecho de la comunidad local a participar a través de sus órganos propios en cuantos intereses le correspondan, en función de lo previsto en la legislación estatal y autonómica.

No cabe duda de que se puede debatir sobre los requisitos de la población de ese núcleo, el número de habitantes o la extensión territorial que han de ser precisos para considerarlo como «municipio»; pero, sin embargo, sí se puede comprobar que la prestación de determinados servicios públicos, en estrictos términos económicos, requieren ciertas condiciones que no las concede el mero reconocimiento de la condición de «municipio».

A pesar de que la Constitución y la nueva legislación de Régimen Local han ampliado el ámbito de actuación de las Corporaciones Locales, apenas se ha avanzado en la reestructuración de la estructura municipal, y en la configuración de ámbitos territoriales más adecuados para la prestación de servicios públicos.

Las normas autonómicas, en general, se han enfrentado a este problema estableciendo limitaciones estrictas a la segregación de municipios y alteración de sus términos, pero no han establecido una decidida política de supresión de municipios, y, si lo han intentado, los movimientos, y opiniones contrarios han obligado a reconducirlos, o eliminarlos.

Así, cuando el Gobierno catalán presentó en 1986 un documento sobre la organización territorial planteando el fomento de la reducción de municipios; asimismo, ocurrió cuando el Gobierno de Navarra presentó el Anteproyecto de Ley Foral sobre Administración Local, en 1989, e igual suerte corrió el documento del Gobierno aragonés, no teniendo éxito en su política de fusiones municipales, implantada en 1988.

De igual modo es posible señalar la experiencia de Castilla y León, pues, al celebrarse en Burgos, en julio de 1992, unas «Jornadas sobre Modernización de la Administración Local» y proponer la figura del «pueblo», implicando la reducción de municipios, inmediatamente surgieron opiniones contrarias, que malograron el proyecto. 
Por ello, tanto en otras Comunidades Autónomas como en Castilla y León se han abandonado las medidas de reestructuración y reducción de Municipios, prefiriendo otras, tratando de superar las insuficiencias de los municipios, ya señaladas; instrumentos que se recogen en los documentos y borradores o proyectos de Castilla y León, que pasamos a analizar.

\section{A) ANTECEDENTES}

Sin perjuicio de otros documentos anteriores (p.ej., los derivados de los trabajos sobre la estructura comarcal de la Comunidad), entre los antecedentes de la Ley de Régimen Local, el Anteproyecto de Ley Municipal de 1994 es muy realista al plantear la preocupante estructura municipal de la región, en su Exposición de Motivos (reproduciéndose en la Ley vigente), detectando, pues, el problema, y proponiendo como medidas más adecuadas el fomento a la integración de municipios inviables en otros más adecuados y la supresión de municipios; si bien el texto reconoce que ambas reformas no son viables a corto plazo, debido a la distancia entre muchas núcleos, la falta de conciencia y la oposición a desaparecer como Administraciones Públicas, por lo que estiman las medidas como no suficientes.

Por ello, este texto de 1994 se apoya directamente en las Mancomunidades Municipales, al considerarlas, por su carácter voluntario y por su capacidad de acomodarse a las necesidades reales, la fórmula idónea para la prestación de determinados servicios que, sin necesitar un marco organizativo superior, exceden de la capacidad aislada de los municipios. Además, regula las Comunidades Vecinales, como entidades de ámbito inferior al municipio, intentando una descentralización funcional, y unos regímenes municipales especiales para municipios y comunidades vecinales de menos de 100 habitantes (ó 250 , en algunos casos) y para municipios menores de 5.000 habitantes. Asimismo, el texto regula la supresión de municipios, estableciendo unos criterios para su aprobación (falta de población o descenso acusado, confusión de núcleos; insuficiencia de medios para prestar los servicios mínimos, falta reiterada de candidatos a elecciones, u otras), que de aplicarse con rigor impondrían una reducción importante de los municipios de la región. Al mismo tiempo, se incluye el límite de 3.000 habitantes para poder segregarse municipios, entre otros requisitos, lo cual, es un complemento adecuado. Finalmente, se prevén medidas de fomento para la fusión de municipios menores de 1.000 habitantes.

$\mathrm{El}$ anteproyecto anterior fue objeto de un debate muy crítico en las Cortes de Castilla y León el 9 de febrero de 1995 (B.O. Cortes, Diario de 
Sesiones, n. ${ }^{\circ}$ 73) y se formularon tanto enmiendas a la totalidad como parciales por los grupos parlamentarios de la oposición (B.O. Cortes n. ${ }^{\circ} 241$ y 242 , de 23 y 24 de marzo de 1995).

Finalmente, el Proyecto fue retirado de su tramitación parlamentaria por la Junta de Castilla y León el 30 de marzo de 1995 (B.O. Cortes n. ${ }^{\circ}$ 244, 7 de abril de 1995).

El nuevo Gobierno Regional, formado después de las elecciones autonómicas de 1995, inició el debate de nuevo al hacer público un Borrador de Proyecto de Ley de Régimen Local a primeros de 1996, que se convertiría en Proyecto de Ley al ser aprobado por la Junta el 5 de diciembre de 1996 (B.O. Cortes, n. $\left.{ }^{\circ} 111,23.12 .1996\right)$.

Respecto a la estructura municipal, la Exposición de Motivos reproduce algunos párrafos del Proyecto anterior, en particular los relativos a la situación municipal y a los instrumentos para solucionarlos, entre los que destaca el apoyo a las Mancomunidades, si bien regula más cuestiones.

Es destacable resaltar que, en materia de segregación de municipios para crear otro, el número de habitantes del nuevo núcleo se rebaja a 1.000 habitantes, en lugar de los 3.000 previstos en el Proyecto de 1995, lo cual no parece muy adecuado, por lo escaso de la población requerida. En cuanto a la supresión de municipios, respecto al Proyecto anterior, se añade la circunstancia de la confusión urbanística entre núcleos, manteniéndose las medidas de fomento a la fusión de municipios menores de 1.000 habitantes, y previéndose Planes Generales de Viabilidad Municipal, de la Consejería de Presidencia y Administración Territorial, con propuestas concretas de fusiones e incorporaciones de municipios.

En cuanto a los servicios mínimos municipales, se prevé la posibilidad de que la Junta de Castilla y León dispense de su prestación a algunos municipios, con ciertas garantías.

Por lo demás, y siguiendo de cerca el proyecto de 1995, el texto se apoya en las Mancomunidades (regulando, también, las Comunidades de Villa y Tierra, los Consorcios, y las Entidades Metropolitanas) y en las Entidades Locales Menores (antes denominadas Comunidades Vecinales); recogiendo, también, regímenes municipales especiales (principalmente, los menores de 100 habitantes o de Concejo Abierto y los que cuenten con menos de 5.000 habitantes).

Finalmente, el texto recoge el régimen de relaciones entre la Comunidad Autónoma y las Entidades Locales, antes regulado en la Ley de 1986. 


\section{B) LA LEY DE RÉGIMEN LOCAL DE CASTILLA Y LEÓN DE 1998: INSTRUMENTOS PREVISTOS}

\section{a) REFERENCIAS GENERALES}

Terminado el trámite parlamentario, el proyecto anterior se convirtió en la Ley 1/1998, de 4 de Junio, de Régimen Local de Castilla y León (BOCYL n. ${ }^{\circ}$ 109, 11-junio, corrección de errores en BOCL de 29-julio).

La nueva Ley mantiene la estructura general ya prevista en el Proyecto de Ley. Disposiciones generales; creación y supresión de municipios, y alteración y deslinde de su términos, competencias y servicios municipales; nombre, capitalidad y símbolos; Mancomunidades y otras Entidades Asociativas; Entidades Locales Menores; Regímenes Especiales; y relaciones entre la Comunidad Autónoma y las Entidades Locales.

\section{b) LOS INSTRUMENTOS PREVISTOS PARA AFRONTAR LOS PROBLEMAS MUNICIPALES DE CASTILLA Y LEÓN}

La claridad de la Exposición de Motivos de la Ley sobre la estructura municipal de la región, que variando poco en relación al Anteproyecto de 1994, sigue siendo muy reveladora de la preocupante situación actual: «gran número de municipios existentes, su dispersión geográfica, y, demográficamente, de escaso tamaño, así como en clara regresión económica y administrativa» (Apdo. 12. ${ }^{\circ}$ ). Es más, la Exposición de Motivos llega a señalar que «la amplitud de competencias frente a la escasez de recursos, hace estéril el principio constitucional de autonomía municipal» (Apdo. 14..$^{\circ}$ ), contemplándose en la Ley la supresión de municipios, con especial atención en el caso de estructuras material y organizativamente inviables (Apdo.15. ${ }^{\circ}$ ).

Sin embargo, siguiendo en este punto a lo señalado por Proyectos anteriores, la EM-Ley de Régimen Local (Apdo.16. ${ }^{\circ}$ ) estima que la reforma de las estructuras municipales a través de una política de fusiones e incorporaciones «no parece posible a corto plazo, entre otros motivos, por la distancia entre los núcleos, por falta de conciencia de las propias comunidades municipales y por su voluntad remisa, cuando no opuesta, a desaparecer como Administraciones Públicas».

Por ello la Ley contempla otros instrumentos: las Comarcas, las Mancomunidades (que se estima una fórmula idónea para la prestación de algunos servicios), las Entidades Locales Menores (a las que pretende dig- 
nificar sus características institucionales) y determinados regímenes municipales especiales.

En sus disposiciones generales, la Ley, después de reconocer al Municipio como la entidad local básica de Castilla y León (art. 2), menciona la Provincia (entre cuyos fines está la de garantizar la prestación integral y adecuada de los servicios municipales) (art.5) y las Comarcas (como ente que agrupa municipios limítrofes con características comunes para la gestión conjunta de sus intereses o servicios) (art. 6); si bien, debido a la rigidez del Estatuto de Autonomía, artículo 19-3. ${ }^{\circ}$, no se establece la regulación general de las Comarcas, lo cual deja un vacío importante en la nueva Ley, al ser ésta reguladora del «régimen local», de todo, con pretensiones de ser una Ley completa.

A continuación, la Ley aborda la creación y supresión de municipios (arts. 9 a 18).

Se prevé la creación de municipios por la segregación de parte del territorio de otro u otros, cuando existan motivos permanentes de interés público y concurran «todas y cada una» de estas condiciones:

- Que se trate de uno o varios núcleos de población territorialmente diferenciados e históricamente consolidados.

- Que el núcleo o núcleos a segregar cuenten con una población mínima de 1.000 residentes, y

- Que el municipio cuya creación se pretenda cuente con territorio y recursos suficientes para el adecuado cumplimento de sus competencias y servicios.

La creación de un municipio por este procedimiento no puede suponer una privación para los municipios segregados de los requisitos anteriores ni una disminución de su población ni de la calidad de servicios.

La creación de municipios por la fusión de otros limítrofes es posible si se cumplen estas condiciones:

- Si separadamente carecen de capacidad o recursos para atender los servicios legales mínimos.

- Si los núcleos se confunden como consecuencia del desarrollo urbanístico, y 
- Cuando se estime necesaria por motivos demográficos, económicos, administrativos de cualquier otro carácter.

Esta fusión supone la supresión de los municipios afectados.

La supresión de municipios, teniendo en cuenta la voluntad de los afectados, será posible por la incorporación de uno o más municipios a otro y otros limítrofes (falta de población o descenso acusado y progresivo de la misma; confusión de núcleos por el desarrollo urbanístico; insuficiencia de medios para prestar los servicios legales mínimos; otras condiciones económicas, administrativas u otras) y por la fusión de municipios, según lo señalado.

El procedimiento de creación o supresión de municipios, que se puede iniciar de oficio por la Administración Autonómica, se resuelve por la Junta de Castilla y León.

La Ley, en esta materia, con buen criterio, establece una serie de medidas de fomento a las fusiones e incorporaciones de municipios con población de 1.000 residentes: fondo de ayudas directas para mejorar la prestación de los servicios de los municipios resultantes; preferencias en su favor en los regímenes generales de ayudas de la Junta; asistencia de las Diputaciones, y coordinación con las medidas de fomento del Estado.

Sin duda, la Ley deja suficiente margen a la Administración Autonómica par emprender una adecuada política de reestructuración municipal, utilizando tanto sus funciones en los procedimientos de creación y supresión de municipios como las medidas de fomento esbozadas, que deberían haberse concretado más o articularse inmediatamente; cuestión que deberá traducirse en la práctica al resolver los expedientes correspondientes.

A continuación, la nueva Ley de Régimen Local, después de referirse a las competencias municipales (de forma repetitiva y poco innovadora), se detiene en la regulación de los servicios mínimos municipales (arts. 20 a 23).

En relación con estos últimos, la Ley considera de interés general y esencial para la Comunidad Autónoma su prestación por los municipios en condiciones de calidad adecuadas, siendo obligados los municipios a su prestación en condiciones de igualdad. A fin de contribuir a su prestación adecuada, se prevé que la Junta establezca niveles homogéneos de prestación de los servicios mínimos; a los cuales se dirigirán preferentemente tanto las funciones asistenciales de las Diputaciones así como las ayudas de la Comunidad Autónoma; así como Planes Generales de Viabilidad Municipal, responsabilidad de la Administración Regional (D. Ad. 2. ${ }^{a}$ ). 
Finalmente, en esta materia, la Ley permite que la Junta pueda dispensar temporalmente a determinados municipios del cumplimiento de los servicios legales mínimos, cumpliendo determinados requisitos (establecimiento difícil; no ser posible su establecimiento a corto plazo; que el esfuerzo fiscal no sea inferior a la media de los municipios de características análogas).

En materia de otros entes locales, con funciones de complementar a los municipios o permitirles desarrollar sus obligaciones de forma más adecuada, la Ley de Régimen Local regula, en primer lugar, las Mancomunidades Municipales (arts. 29 a 41), como entes de asociación voluntaria de municipios para la ejecución en común de obras y servicios determinados de su competencia.

De su régimen jurídico, para nuestra materia, destacamos la posibilidad de que algunas sean declaradas de interés comunitario (si su ámbito territorial concuerda sustancialmente con espacios de ordenación territorial para la prestación de servicios estatales, autonómicos o provinciales), por su financiación preferente y otros beneficios, a determinar reglamentariamente.

Por lo demás, la regulación de las Mancomunidades sigue de cerca la legislación básica, con escasas novedades.

Desde el punto de vista de conseguir una Ley más completa, hubiera sido deseable mayor concreción en cuanto a su régimen financiero y a las ayudas; así como establecer el contenido de los Estatutos, al permitirlo la legislación básica.

Junto a las Mancomunidades, el Título VI de la Ley incluye las Comunidades de Villa y Tierra, de carácter histórico-tradicional (arts. 42 a 44), las Entidades Metropolitanas, como entes supramunicipales para la planificación conjunta y la gestión coordinada de determinadas obras y servicios (arts. 45 a 47), y los Consorcios, en los que participan otras Administraciones Públicas y entidades privadas sin ánimo de lucro para la realización de actuaciones conjuntas, la coordinación de actividades y la conservación de fines de interés común (art. 48).

Con especial minuciosidad, la nueva Ley regula, en el Título VII (arts. 49 a 71), las Entidades Locales Menores, destacándose la importancia que tienen en Castilla y León por el amplio número de preceptos que le dedica el texto legal (en concreto, existen 2.230, actualmente).

Estas Entidades tienen un ámbito territorial inferior al Municipio, con la finalidad de llevar a cabo la administración descentralizada de núcleos 
de población separados, teniendo personalidad y capacidad jurídica para el ejercicio de sus competencias (relativas a su patrimonio; las vías urbanas, caminos, fuentes, lavaderos y abrevaderos; y otras que le delegue el Ayuntamiento del que dependa, no siendo posible la delegación de la ordenación, gestión y disciplina urbanística); gozando, para ello, de un buen número de potestades públicas.

Es destacable que el procedimiento finaliza con la intervención de la Junta de Castilla y León; con lo que ésta dirigirá la política relativa a la estructura municipal de la región, al valorar la existencia de los requisitos exigidos para su creación (territorio y recursos, número mínimo de habitantes, etc.).

La propia Ley (D. Ad. 3. ${ }^{\mathrm{a}}$ y $4 .^{\mathrm{a}}$ ) procede a suprimir automáticamente las Entidades Locales Menores que en la fecha de entrada en vigor del texto no tuvieran población, previendo el inicio del procedimiento de supresión en determinados casos (incumplimiento de competencias; no cubrir los órganos rectores; motivos de necesidad económica o administrativa; o si lo solicita la mayoría de los vecinos).

Con mucho detalle, lo cual sorprende al compararlo con otros entes locales regulados en la propia Ley, el texto autonómico regula los recursos de las Entidades Locales Menores.

A continuación, la Ley de Régimen Local de Castilla y León, con un criterio muy realista, regula los regímenes municipales especiales (Título VIII, arts. 72 a 80), incluyendo el Concejo Abierto (para municipios con menos de 100 habitantes, que lo utilicen tradicionalmente 0 , en determinados casos, con menos de 250 habitantes), los municipios menores de 5.000 habitantes (facilitando un funcionamiento; elaborando un Reglamento orgánico si el Ayuntamiento no lo aprueba, etc.), los municipios histórico-artísticos (que complementará lo previsto en la legislación específica) y los municipios cabecera de zonas u otros de carácter específico (mineros, etc.).

Finalmente, la nueva Ley regula las relaciones entre la Comunidad Autónoma, y las Entidades Locales (Título IX, arts. 81 a 110), integrando lo regulado por la Ley 6/1986, de 6 de junio (que se deroga), en concreto las delegaciones y transferencias a otros entes locales (diputaciones, municipios mayores de 5.000 habitantes, mancomunidades, etc.) y el sistema organizativo correspondiente (Consejo de Provincias, Comarcas y otras Entidades Locales); junto a técnicas de coordinación (así, de las Diputaciones y de sus Planes Provinciales de Cooperación; de especial interés para los municipios a los que van destinados). 
Respecto a su desarrollo reglamentario, en 1999 la Consejería de Presidencia y Administración Territorial elaboró borradores de Decretos sobre Mancomunidades y otros entes asociativos, sobre el Registro de Entidades locales y sobre el Consejo de las Provincias. Posteriormente, se aprobaron el Decreto 215/2000, de 19 de octubre, por el que se crea el Registro de Entidades Locales de la Comunidad de Castilla y León y se establece su organización y funcionamiento (BOCYL del 23) y el Decreto 216/2000, de 19 de octubre, por el que se establece el régimen orgánico y de funcionamiento del Consejo de Provincias de la Comunidad de Castilla y León (BOCYL del 23); quedando pendientes de regulación las Mancomunidades y los otros Entes Asociativos.

Por otra parte, pero en este mismo sentido, y de acuerdo con lo establecido en la Ley de Régimen Local, debe destacarse, asimismo, el Decreto 53/2002, de 4 de abril, regulador del Fondo de Cooperación Local de la Comunidad de Castilla y León (BOCYL del 8), como instrumento de cooperación económica de la Comunidad con las Entidades Locales.

\section{c) EL PACTO LOCAL AUTONÓMICO}

En un intento de potenciar la actividad de las Entidades Locales, siguiendo el principio comunitario de subsidiariedad y la conclusión del Pacto Local estatal de 1999, el Presidente de la Junta de Castilla y León asume el compromiso de presentar, y llegar al consenso, un Pacto Local Autonómico, para lo cual, mediante Decreto 48/2002, de 27 de marzo, se crea la Comisión de Coordinación y Desarrollo del Pacto Local (BOCYL de 2 de abril), con funciones de asesoramiento, informe, iniciativa y propuestas en la materia.

La Consejería de Presidencia y Administración Territorial preparó un documento marco en la materia, que la Junta de Castilla y León aprobó por Acuerdo de 17 de octubre de 2002, relativo a la Propuesta para la consecución del Acuerdo del Pacto Local de Castilla y León; que no ha sido aprobado aún.

La propuesta incluye medidas de refuerzo competencial (medidas de potenciación de competencias ya atribuidas y medidas de traspaso competencial en materia de acercamiento de los servicios a los ciudadanos, traspasos sobre autorizaciones y licencias, traspasos en materia de inspecciones y licencias, y traspasos sobre registros públicos), medidas de participación de las Entidades Locales en la toma de decisiones (medidas de desarrollo por convenios y medidas de cooperación orgánica, general y sectorial) y medidas de vertebración administrativa del territorio. 


\section{LAS ADMINISTRACIONES LOCALES EN LAS LEYES DE URBANISMO Y ORDENACIÓN DEL TERRITORIO DE CASTILLA Y LEÓN}

Tal como hemos señalado al analizar la distribución de competencias, tanto los Municipios como las Provincias pueden intervenir, y ejercer competencias, en materia de ordenación del territorio y urbanismo, de acuerdo con lo previsto en la Ley de Bases de Régimen Local y en la legislación autonómica correspondiente (tanto general como sectorial); teniendo en cuenta la legislación urbanística del Estado.

En este sentido, el artículo 20 de la Ley de Régimen Local de Castilla y León prevé competencias de los municipios en materia de «ordenación, gestión, ejecución y disciplina urbanística» (letra d, apdo.1. ${ }^{\circ}$ ), en los términos previstos en la legislación estatal y autonómica. Para el ejercicio de estas competencias, el apdo. $2 .^{\circ}$ del mismo precepto prevé que los Municipios puedan crear y gestionar equipamientos e infraestructuras, planificar su ubicación, programar actividades y prestar cuantos servicios públicos deseen.

Particular importancia le concede la Ley autonómica (arts. 21 a 23) a la prestación de los servicios mínimos municipales, previstos en el artículo 26-LBRL; algunos de los cuales tienen estrecha relación con el urbanismo (acceso a núcleos de población; pavimentación de vías públicas).

La Ley de Régimen Local prevé, potenciándolas de forma clara, las Mancomunidades de Municipios, como asociaciones municipales para la ejecución en común de obras y servicios determinados de su competencia (arts. 29 a 41).

Además, la Ley autonómica regula las Provincias (art. 5), destacando sus funciones de apoyo a los Municipios; y prevé las Comarcas, como agrupación de municipios limítrofes con características comunes para la gestión conjunta de sus intereses o servicios y para la colaboración en el ejercicio de sus competencias (art. 6).

De acuerdo con lo previsto en la Constitución, el Estatuto de Autonomía de Castilla y León y la Ley de Bases de Régimen Local, como es sabido y ya hemos señalado, la fijación concreta de las competencias municipales se ha de establecer en la legislación estatal y autonómica correspondiente; y así lo establece la Ley de Régimen Local de Castilla y León en materia urbanística, en su artículo $20-1{ }^{\circ}, \mathrm{d}$, tal como hemos señalado. Sin embargo, la determinación detallada de las mismas se ha de fijar 
en la legislación específica; en este caso la urbanística y la de ordenación del territorio, en su caso.

Esta legislación está constituida por la Ley 5/1999, de 8 de abril, de Urbanismo de Castilla y León (modificada por Ley 10/2002, de 10 de julio, BOCYL del 12, y por Ley 21/2002, de 27 de diciembre, BOCYL del 30, y cuya Tabla de Vigencias de los Reglamentos Urbanísticos Estatales se aprobó mediante Decreto 223/1999, de 5 de agosto, BOCYL del 10) y por la Ley 10/1998, de 5 de diciembre, de Ordenación del Territorio de Castilla y León (BOCYL del 10).

Teniendo en cuenta la consolidada y tradicional posición central de los Municipios en la ordenación urbanística, bien conocida, y la importante, y preocupante, estructura municipal de Castilla y León, siendo considerados como la entidad local básica de la Comunidad (art. 25-EACYL), la LUCYL establece que la actividad urbanística pública, y en especial su dirección y control, corresponde, de forma general y habitual, a los Municipios; sin perjuicio de las competencias que corresponden a la Comunidad Autónoma y a otras Administraciones Públicas (arts. 3-1. y 132-1. ${ }^{\circ}$, LUCYL). De esta forma, la LUCYL se caracteriza por ser un texto favorecedor de la potenciación municipal en materia urbanística, y respetuoso con el principio de autonomía local, reconocido y protegido por la Constitución y el Estatuto de Autonomía.

Establecido lo anterior, la LUCYL reconoce importantes competencias a los Municipios:

- Autorización de usos en suelo rústico, por sí mismos (municipios con población igual o superior a 20.000 habitantes o que cuenten con Plan General) o participando en la decisión de la Comisión Territorial de Urbanismo (en los restantes) (art. 25-LUCYL).

- Participación, de forma preferente, y, según los casos, aprobación de los instrumentos de planeamiento urbanístico, así como en relación a la revisión y modificación de los mismos (arts. 50 a 58-LUCYL). También, en cuanto a la publicación y notificación de los acuerdos de aprobación de los anteriores, según los supuestos (art. 61-LUCYL).

- Destacable participación en la gestión urbanística no sólo creando entidades específicas (art. 67-LUCYL), sino materialmente en la propia gestión (de actuaciones aisladas o integradas, arts. 69 y ss.LUCYL, en particular, en relación con los Proyectos de Actuación), y en las formas complementarias de gestión (arts. 93 y 94-LUCYL). 
- Otorgamiento o denegación de las licencias urbanísticas (arts. 97 a 105-LUCYL).

- Dictar órdenes de ejecución (art. 106-LUCYL).

- Declarar la ruina de inmuebles (art. 107) y adopción de medidas en caso de ruina inminente (art. 108-LUCYL).

- Formación y mantenimiento del Registro de Inmuebles en Venta Forzosa, para los municipios que superen 20.000 habitantes o cuenten con Plan General (art. 109-LUCYL).

- En estos Municipios, mantener el sistema de inspección técnica de las construcciones, previsto en el artículo 110-LUCYL.

- En materia de protección de la legalidad urbanística, es muy visible la potenciación del papel de los Municipios prevista en la Ley, ya que el artículo 111 establece que le corresponden competencias en materia de inspección urbanística (art. 112), de adopción de medidas de protección y restauración de la legalidad urbanística (arts. 113114 y 118 a 120) y en materia de sanciones (arts. 115 a 117 y 121).

- Constituir y gestionar Patrimonios Públicos Municipales de Suelo, según los casos (art. 123-LUCYL).

- Para los municipios que cuenten con más de 20.000 habitantes o con Plan general, la elaboración de Programas Municipales de Suelo, y ejercitar los derechos de tanteo y retracto (arts. 129 y 131-LUCYL).

- Realizar las funciones derivadas de la regulación de la información urbanística, la audiencia a los interesados y la publicidad de los instrumentos urbanísticos (arts. 141 a 144 y 146 a 148-LUCYL).

- Medidas de fomento (Disposición Adicional 3. ${ }^{a}$, LUCYL); y

- Adaptación a la nueva Ley (Disposiciones Transitorias-LUCYL).

Además, el artículo 132-LUCYL posibilita la delegación de competencias autonómicas en favor de los Municipios que superen 20.000 habitantes o cuenten con Plan General.

La Ley de Ordenación del Territorio, prácticamente, no reconoce competencias municipales, al establecer que tal competencia le corresponde a la Administración autonómica, y, en concreto, a la Junta de Castilla y León (art. 3). 
No obstante, se prevé su participación en la elaboración de las Directrices de Ordenación de Castilla y León (art. 12) y de las Subregionales (art. 18), así como la iniciativa y participarán en la elaboración de los Planes y Proyectos Regionales (art. 24). Además, es destacable que la iniciativa para elaborar las Directrices Subregionales puede partir de los Municipios, con ciertos requisitos (art. 18-LOTCYL).

En cuanto a la organización urbanística municipal, la LUCYL deja un amplio margen de actuación a la potestad organizatoria propia, si bien menciona expresamente la posibilidad de crear órganos desconcentrados o gerencias urbanísticas; fomentando claramente la creación de Mancomunidades Municipales en la materia, siguiendo una tradicional línea de actuación de la Comunidad, ratificada en la Ley de Régimen Local (art. 134-LUCYL).

Las Provincias, como entes que también gozan de autonomía, según lo previsto en la Constitución y el Estatuto de Autonomía, ven precisadas sus competencias en la correspondiente legislación estatal y autonómica, destacándose, en el artículo 36-LBRL, la coordinación de los servicios municipales; la asistencia a los Municipios en materia jurídica, económica y técnica; la prestación de servicios públicos de carácter supramunicipal y supracomarcal; y el fomento y administración de los intereses peculiares de la provincia. En tal sentido se expresa el artículo 5-3. ${ }^{\circ}$ de la Ley de Régimen Local de Castilla y León.

De acuerdo con lo anterior, el artículo 133-LUCYL prevé las competencias provinciales (haciendo referencia, la Ley, a las Diputaciones Provinciales, con cierta confusión, vid. artículo $31-1 .^{\circ}$ y $3 .^{\circ}$, LBRL) siguientes:

- La asistencia y cooperación técnica, jurídica y económica con los Municipios, con el objeto de facilitar el adecuado ejercicio de sus competencias, y en particular el cumplimiento de las determinaciones del planeamiento urbanístico.

- La emisión de informes técnicos y jurídicos en el procedimiento de otorgamiento de las licencias urbanísticas municipales (art. 991. $\left.{ }^{\circ}, \mathrm{b}, \mathrm{LUCYL}\right)$.

- Las atribuidas expresamente en otros preceptos de la Ley; entre las que destacamos:

- Participación en el procedimiento de elaboración de los instrumentos de planeamiento urbanístico (art. 52-4. ${ }^{\circ}$, LUCYL). 
- Participar en convenios urbanísticos (art. 94-LUCYL).

- Formación y mantenimiento de Registro de Inmuebles en Venta Forzosa, a solicitud de los Municipios con menos de 20.000 o que no cuenten con Plan General (arts. 109-LUCYL).

- Competencias en materia de protección de la legalidad urbanística (inspección, protección y restauración, sanciones), si los municipios no las ejercen; las Diputaciones Provinciales podrán ejercerlas directamente o aportando los medios técnicos y económicos de los que careciese el Ayuntamiento correspondiente (art. 111-2. ${ }^{\circ}$, LUCYL). Sin duda, si se ejercen directamente estas competencias, suponen un instrumento de consolidación de las Provincias en materia urbanística, al darle sustantividad propia a las mismas. Además, debe resaltarse que si el expediente sancionador lo tramita la Diputación Provincial directamente, al amparo del artículo 111-2. le corresponderá a ella el importe de la sanción, si el Ayuntamiento no ejerciese la competencia, previo requerimiento para ello.

- Constituir, potestativamente, Patrimonios Públicos de Suelo (art. 123-LUCYL).

- Proporcionar el servicio de consulta urbanística de forma obligatoria, cuando el Municipio carezca de los medios necesarios (art. 146-3. $\left.{ }^{\circ}-\mathrm{LUCYL}\right)$.

- En relación estrecha con el anterior supuesto, el art. 144-2. LUCYL prevé que la Diputación atienda las consultas urbanísticas de los particulares al menos una vez a la semana, en defecto de actuación de los Municipios; y, entre otras.

- Medidas de fomento económico (Disposición Adicional 3. LUCYL).

- Contribuir a la elaboración y financiación de los instrumentos de planeamiento y gestión urbanísticos, fomentando su homogeneidad y calidad técnica (art. 133-2. ${ }^{\circ}$ LUCYL).

- Ejercer las competencias que le delegue la Administración regional, de acuerdo con lo previsto en la Ley de Régimen Local (art. 1333. ${ }^{\circ}$, LUCYL).

En materia de ordenación del territorio, al igual que en el caso de los Municipios, las Diputaciones Provinciales participan en el procedimiento 
de elaboración de las Directrices Regionales y Subregionales (arts 12 y 18), así como en el de los Planes y Proyectos Regionales (art. 24); destacando la iniciativa en la elaboración y propuesta de las Directrices Subregionales y de los Planes y Proyectos Regionales (arts. 18 y 20-LOTCYL).

En materia de organización urbanística, el artículo $133-2 .^{\circ}$, LUCYL, establece que las Diputaciones Provinciales «dispondrán de un servicio de gestión urbanística con la finalidad de asumir las tareas urbanísticas que dispone esta Ley». Con ello, se plasma claramente el interés del legislador autonómico en que las Diputaciones tengan una entidad mucho mayor en materia urbanística; interés coherente con la complejidad de la estructura municipal de Castilla León. Sin embargo, las decisiones concretas sobre esta cuestión le corresponden a las propias Diputaciones Provinciales.

Además, y siguiendo el supuesto de los Municipios, el artículo 134LUCYL prevé que las Diputaciones puedan crear órganos desconcentrados y gerencias urbanísticas para gestionar sus competencias.

El hecho de que los sectores del urbanismo y la ordenación del territorio afecten a varias materias-competencias, así como a varias Administraciones Pública, provoca la necesidad de seguir pautas de colaboración y coordinación administrativas; tal como ha destacado la STC 77/1984, de 3 de junio (FJ n. ${ }^{\circ}$ ), entre otras.

En este sentido, la Ley de Ordenación del Territorio establece diversas fórmulas de coordinación administrativa (art. 27):

- Se ratifican los principios de coordinación, cooperación y participación en las relaciones entre Administraciones Públicas (art. 27$\left.1 .^{\circ}\right)$.

- Promoción por la Junta de Castilla y León de la participación de otras Administraciones, y, en especial, de las Entidades Locales, en la elaboración de los instrumentos de ordenación del territorio (art. $\left.27-2 .^{\circ}\right)$.

- Previsión, en la legislación urbanística, de las condiciones para que el planeamiento urbanístico justifique su coherencia con los instrumentos de ordenación del territorio, principalmente (art. 27-3. ${ }^{\circ}$ ).

- Conocimiento por la Administración Autonómica de los planes y programas estatales, sometiéndolos a informe del Consejo de Urbanismo y Ordenación del Territorio (art. 27-4. ${ }^{\circ}$ ). 
- Previsión de convenios para resolver conflictos con la Administración Estatal (art. 27-4..$^{\circ}$.

- El Consejo de Urbanismo y Ordenación del Territorio (art. 29).

Por su parte, la Ley de Urbanismo también incluye algunas técnicas de coordinación administrativa:

- El Consejo de Urbanismo, señalado, y las Comisiones Territoriales de Urbanismo (arts. 137 y 138).

- Ratificación de los principios de coordinación, cooperación, concertación e información recíproca en las relaciones entre Administraciones Públicas (art. 140-1. ${ }^{\circ}$ ); con expresa referencia a la coordinación entre las competencias urbanísticas y sectoriales (art. $\left.140-2 .^{\circ}\right)$.

- Información recíproca entre las Administraciones Públicas (art. $\left.140-3 .^{\circ}\right)$ :

- Notificación de los acuerdos urbanísticos autonómicos a las demás Administraciones, y, en particular, a los Municipios afectados.

- Los Municipios remitirán a la Consejería de Fomento un ejemplar de los instrumentos de planeamiento y gestión urbanísticas, con los planos; y debidamente diligenciados.

- Colaboración de Municipios y Diputaciones con la Administración Autonómica en materia de información y cartografía urbanísticas.

- Colaboración de Municipios y Diputaciones con otras Entidades de Derecho Público para el ejercicio de sus competencias urbanísticas (art. 134-1. ${ }^{\circ}$, LUCL). 
LA ESTRUCTURA MUNICIPAL DE CASTILLA Y LEÓN: INCIDENCIA DE LA LEGISLACIÓN SOBRE RÉGIMEN LOCAL...

\section{BIBLIOGRAFÍA BÁSICA}

Belando Garín, B. y otros, Legislación Local, 3. a ed., Ed. Tirant Lo Blanch, Valencia, 2003.

Blanco, A. (Ed.). y otros, Castilla y León. Envejecimiento y mundo rural, Ed. Fundación Encuentro-Caja España, León, 2002.

Calonge Velásquez, A., «La planta municipal y las Entidades Locales Menores en Castilla y León», REAL, n. ${ }^{\circ} 285 / 2001$.

Consejería de Medio Ambiente y Ordenación del Territorio:

- Programa para la Legislatura 1995-1999, Valladolid, 1995.

- Memoria, 1998, Valladolid, 1999.

- Modelo funcional de la territorialización de servicios en Castilla y León, Valladolid, 1994.

- Castilla y León. Hipótesis de modelo territorial, Madrid, 1996.

Consejería de Presidencia y Administración Territorial (J.C. y L.),:

- Catálogo de Mancomunidades Municipales de Castilla y León, Valladolid, 1991 y 1993.

- Recopilación Normativa de la Comunidad Autónoma de Castilla y León, Ed. JC-L., Valladolid, 1999. Apéndice de 2001 [Asimismo, ténganse en cuenta las ediciones de la misma obra de 1990 y 1993].

- Memoria, 1999, Valladolid, 2000.

Fernández de Gatta Sánchez, D., Fernando Pablo, M., y otro, Legislación Básica de Castilla y León, Ed. Tecnos, Madrid, 1991.

Fernández de GatTa SÁnchez, D.:

- «El Régimen Normativo de las Mancomunidades Municipales», RVAP, n. ${ }^{\circ} 37 / 1993$.

- «Los problemas de coordinación de las actividades sectoriales sobre el territorio, con especial referencia a Castilla y León», Revista de Derecho Urbanístico y Medio Ambiente, n. ${ }^{\circ}$ 144/1995.

- Manual del Alcalde, Ed. Diputación de Valladolid, Valladolid, 1998.

- «Aspectos jurídicos de las relaciones entre Ordenación del Territorio y Urbanismo. Especial referencia a la Legislación Autonómica», Revista 
de Estudios Locales (CUNAL), Julio, 1999, Extraordinario sobre «Urbanismo».

- «Los problemas de la estructura municipal de Castilla y León: instrumentos y soluciones de la nueva Ley de Régimen Local», VI Congreso de Economía Regional de Castilla y León, Comunicaciones, vol. II, Ed. Consejería de Economía y Hacienda (J.C y L.), Salamanca, 1998. También publicado en El Consultor, n. ${ }^{\circ}$ 19, 15 de Octubre de 1999.

- «El Régimen Jurídico de los Municipios sin planeamiento», en SÁnchez Goyanes, E. (Dir.), Marinero Peral, A., y Fdez. De Gatta Sánchez, D. (Coords.), y otros, Derecho Urbanístico de Castilla y León, Ed. El Consultor y Junta de Castilla y León (Consejería de Fomento), Madrid, 2000.

- «Las Normas Urbanísticas Municipales», en SÁnchez Goyanes, E. (Dir.), Marinero Peral, A., y Fdez. De Gatta Sánchez, D. (Coords.), y otros, Derecho Urbanístico de Castilla y León, Ed. El Consultor y Junta de Castilla y León (Consejería de Fomento), Madrid, 2000.

- «La organización y coordinación administrativas de la Comunidad de Castilla y León en materia de Urbanismo y Ordenación del Territorio», en Sánchez Goyanes, E. (Dir.), Marinero Peral, A., y Fdez. De Gatta SÁnchez, D. (Coords.), y otros, Derecho Urbanístico de Castilla y León, Ed. El Consultor y Junta de Castilla y León (Consejería de Fomento), Madrid, 2000.

- «El Planeamiento Urbanístico», en Quintana LóPez, T. (Dir.), y otros, Derecho Urbanístico Estatal y Autonómico, Ed. Tirant Lo Blanch, Valencia, 2001.

- «Infraestructuras y desarrollo económico en la Legislación de Ordenación del Territorio de la Comunidad de Castilla y León», VIII Congreso de Economía Regional de Castilla y León (Valladolid, 28 a 30 de Noviembre de 2002), Comunicaciones, Tomo II, Ed. Consejería de Economía y Hacienda (J. C. y L.), Salamanca, 2002.

- «Las Leyes de Ordenación del Territorio y Urbanismo de Castilla y León: Nuevos retos futuros para las Administraciones Públicas», en VArios Autores, Panorama Jurídico de las Administraciones Públicas en el siglo XXI. Homenaje al Prof. Dr. D. Eduardo Roca Roca, Ed. INAP-BOE, Madrid, 2003.

Fernández Carballal, A., El régimen jurídico del Urbanismo en España. Una perspectiva competencial, Ed. INAP-MAP, Madrid, 2001. 
Junta de Castilla y León, Normativa de Ordenación del Territorio y Urbanismo de Castilla y León, 4. . ed., Valladolid, 2001.

JunTa de CAstilla y León, «Propuesta para la consecución del Acuerdo del Pacto Local de Castilla y León», Valladolid, 2002.

Marinero Peral, A.,:

- «El sistema de planeamiento urbanístico: Los principios inspiradores», en Sánchez Goyanes, E. (Dir.), Marinero Peral, A., y Fdez. De Gatta SÁncheZ, D. (Coords.), y otros, Derecho Urbanístico de Castilla y León, Ed. El Consultor y Junta de Castilla y León (Consejería de Fomento), Madrid, 2000.

- «La Ley 5/1999, de Urbanismo de Castilla y León: Problemas de aplicación», en Jornada sobre la Ley de Urbanismo de Castilla y León, Consejería de Fomento, JC-L, Valladolid, 19 de Mayo de 2000 (texto original mecanografiado).

Mozo Aмо, J., «El municipalismo. Presente y futuro del pequeño Municipio. Especial referencia a Castilla y León», Revista de Estudios Locales (CUNAL), n. ${ }^{\circ}$ 60/2002.

Quintana LóPez, T., «Las Comarcas en Castilla y León. La Comarca de El Bierzo», Revista Aragonesa de Administración Pública, n. ${ }^{\circ}$ 3/1993.

Quintana López, T. (Dir.) y otros, Derecho Urbanístico Estatal y Autonómico, Ed. Tirant Lo Blanch, Valencia, 2001.

QuintANA LÓPEZ, T., «Las Diputaciones en Castilla y León. Balance y perspectivas», REAL, n. ${ }^{\circ} 285 / 2001$.

Quintana LóPez, T. y otros, Código de Legislación Urbanística y Jurisprudencia concordada, Ed. Tirant Lo Blanch, Valencia, 2003.

SÁnchez Blanco, A., «La Comarca en Castilla y León: problemática jurídico-institucional», REALA n. ${ }^{\circ} 230 / 1986$.

Sánchez Goyanes, E. (Dir.), Marinero Peral, A., y Fdez. De Gatta SánCHEz, D. (Coords.), y otros, Derecho Urbanístico de Castilla y León, Ed. El Consultor y Junta de Castilla y León (Consejería de Fomento), Madrid, 2000.

SÁnchez Goyanes, E., «La Ley 5/1995, de 8 de Abril, de Urbanismo de Castilla y León. Un buen ejemplo», El Consultor, n. ${ }^{\circ} 11$, de 15-Junio-1999. 
Sánchez Goyanes, E., y Fdez. De Gatta Sánchez, D., «La Ley de Ordenación del Territorio de Castilla y León: Aspectos generales e instrumentos», en Sánchez Goyanes, E. (Dir.), Marinero Peral, A., y Fdez. De Gatta SÁnchez, D. (Coords.), y otros, Derecho Urbanístico de Castilla y León, Ed. El Consultor y Junta de Castilla y León (Consejería de Fomento), Madrid, 2000.

SÁnchez Madariaga, I., Introducción al Urbanismo. Concepto y metodos de planificación urbana, Alianza Ed., Madrid, 1999.

Varios Autores, Ordenación del Territorio y Medio Ambiente, II Congreso Mundial Vasco, Ed. IVAP, Bilbao, 1988.

VArios Autores, I Seminario Iberoamericano sobre Mancomunidades Municipales, Ed. J.C.-L., Segovia, 1997.

Varios Autores, monográfico sobre «Urbanismo», Revista de Estudios Locales (CUNAL), julio de 1999, dirgido por SÁnChEz Goyanes, E. y Castelao Rodríguez, J.

Villalba Casas, J.J., «Nuevo panorama del Urbanismo en Castilla y León», El Consultor n. ${ }^{o}$ 7, 15 de Abril de 2000. 